\title{
Relationships among the $Y$ balance test, Berg Balance Scale, and lower limb strength in middle-aged and older females
}

\author{
Dong-Kyu Lee ${ }^{1}$, Min-Hyeok Kang ${ }^{1}$, Tae-Sik Lee ${ }^{2}$, Jae-Seop $0 h^{3}$
}

\begin{abstract}
Background: Older females have less dynamic postural control and muscle strength than do middle-aged females. Aging-related strength losses may limit balancing performance. Objective: The purpose of this study was to investigate the ability of the Y Balance Test (YBT) and lower limb strength to discriminate between females in 2 age groups, the relationship between YBT distance and the Berg Balance Scale (BBS), and the degree to which performance on YBT distance is related to lower limb strength in middle-aged and older females. Method: The 40 healthy, independently active females were divided into 2 groups: older and middle-aged. The participants underwent measurements of YBT distance using the YBT, maximal muscular strength of the lower limbs using a handheld dynamometer, and the BBS. Results: The YBT distance in 3 directions and lower limb muscle strength for both lower limbs were significantly lower in the older adults than in the middle-aged group. A moderate correlation but insignificant correlation was found between the YBT composite distance and the BBS score. In the older females, YBT distance was significantly positively correlated with strength of the knee flexor and hip abductor. In the middle-aged group, YBT distance was significantly positively correlated with strength of the knee flexor and hip extensor. Conclusions: Performance on the YBT was influenced by the strength of lower limb. We suggested that YBT can be used to alternative as a measurement of dynamic balance. Proper training programs for older people could include not only strengthening exercises but also YBT performance to improve balance.
\end{abstract}

Keywords: aging; Berg Balance Scale; lower limb strength; physical therapy; Y Balance Test.

\section{HOW TO CITE THIS ARTICLE}

Lee D-K, Kang M-H, Lee T-S, Oh J-S. Relationships among the Y balance test, Berg Balance Scale, and lower limb strength in middle-aged and older females. Braz J Phys Ther. 2015 May-June; 19(3):227-234. http://dx.doi.org/10.1590/bjpt-rbf.2014.0096

\section{Introduction}

In older adults, high levels of lower limb strength and balance are important prerequisites for the independent and successful performance of activities of daily living. Age-related musculoskeletal changes lead not only to muscle strength and mass decline but also limit balance and gait ${ }^{1,2}$. These changes are closely related to the incidence of falls. In older adults, falls can cause severe injuries such as hip fractures $(50 \%)$, arm fractures (13\%), and head injuries (10\%) or even death ${ }^{3,4}$.

Aging is associated with diminished muscle strength ${ }^{5}$, changes in posture ${ }^{6}$, and lower postural stability ${ }^{7}$. The decrease in strength seems to be explained, to a great extent, by the reduction in muscle mass, perhaps related to a decline in the intensity of daily physical activities ${ }^{8}$. Previous studies have reported dynamic balance decreases with age $e^{9,10}$. Bouillon and
Baker ${ }^{10}$ reported that postural control scores based on the Star Excursion Balance Test (SEBT) were lower in older females than in younger females. However, there is a lack of age-related differences in various measures of lower limb strength and dynamic balance between middle-aged and older females.

The Berg Balance Scale (BBS) has been widely used to assess dynamic and static balance in older adults. The BBS includes 14 items that are common in everyday life. In the clinical setting, the BBS is easy to apply and assesses balance in older adults to help predict the risk of falling ${ }^{11}$. However, some studies have reported that the BBS is unreliable for screening the risk of falls among older adults ${ }^{12-14}$. Despite its high reliability and validity ${ }^{11}$, the BBS may not be the most appropriate test of mobility or balance. Because this clinical observational tool is

\footnotetext{
${ }^{1}$ Department of Rehabilitation Science, Graduate School, INJE University, Gimhae, South Korea 
scored on an ordinal scale, it may not be sufficiently sensitive to change, particularly in active older adults with high levels of balancing ability. Given the low sensitivity of the BBS for balance limits, and that it has a ceiling effect, a new test should be developed to measure balance in a more challenging way for active older women.

The Y Balance Test-YBT(Move2Perform, Evansville, IN, USA) is a dynamic balance test that may be less likely than the BBS to demonstrate a ceiling effect. The YBT is essentially an instrumented version of the components of the SEBT, and it was developed to improve measurement repeatability and to standardize the performance of the test ${ }^{15}$. The YBT incorporates reaching in 3 directions (anterior, posteromedial, and posterolateral) with the unsupported lower limb while in a single-limb stance on a centralized stance platform. In sports players, the YBT can be used for injury prediction and performance discrimination ${ }^{16}$. The benefits of the YBT are that it has a standard protocol and high inter-rater (0.991.00) and intra-rater $(0.850 .91)$ reliabilities ${ }^{13}$. However, there was no previous study demonstrating the reliability of the YBT in middle-aged and older females. Nevertheless, the YBT can be used to test and train simultaneously, which is beneficial for the development of rehabilitation and training programs.

From a therapist's point of view, knowledge of the relationship between the strength of the lower limb muscles and balance may be important for both the identification of older adults with an increased risk of falling and the development of fall-preventive training programs. Despite evidence demonstrating the importance of prevention of falling in older females, the relationship between the strength of the lower limbs and balance is not fully understood. By understanding the relationship between the YBT and strength, we can obtain more clinical information regarding which exercises would best help middle-aged and older females to achieve a long YBT distance. We believe that repeated investigation of the training to extend the YBT distance during one-leg standing will provide beneficial information to clinicians for prevention of falls in older females. Thus, the first purpose of this study was to compare lower limb strength and the YBT distance in 3 directions in middle-aged and older females. The second purpose was to assess any relationship between the YBT distance and the BBS in older females and to determine any relationship between the YBT distance and lower limb strength in middle-aged and older females.

\section{Method}

\section{Study design}

This cross-sectional study required each participant to be assessed for YBT distance (anterior, posteromedial, and posterolateral), maximal muscular strength of the lower limbs (hip extension, hip flexion, hip abduction, knee extension, knee flexion, and ankle dorsiflexion), and BBS score. The study sample was divided into 2 groups at 65 years: middle-aged and older women. This was a correlational study of relationships among YBT distance, the BBS, and lower limb strength in middle-aged and older females. All subjects read and signed an informed consent form approved by the Inje University Ethics Committee, Gimhae, Gyeongsangnam-Do, South Korea (approval number 2014067) for Human Investigations prior to participation.

\section{Subjects}

The 40 female participants, aged $45-80$ years, volunteered for this study and were categorized into age groups: middle-aged (45-60 years) or older (70-80 years). There were 20 middle-aged females $(53.9 \pm 5.0$ years; $56.0 \pm 6.2 \mathrm{~kg} ; 159.8 \pm 4.7 \mathrm{~cm})$ and 20 older females $(77.5 \pm 2.7$ years; $51.7 \pm 7.7 \mathrm{~kg}$; $152.8 \pm 4.4 \mathrm{~cm})$. The older females were recruited from senior citizen centers in Haeundae, Busan, Republic of Korea. The middle-aged females were recruited from the community. Participants were healthy, living independently, were self-ambulatory without a cane or walker, and had no history of falls. Participants with self-reported neurological disease, musculoskeletal problems, visual impairment, or vestibular disease were excluded. Older females with comprehension deficits or disabilities that might limit the tasks of performance on the YBT or the BBS were also excluded.

\section{Y Balance Test}

The YBT is a reliable and valid tool for quantitative balance assessment ${ }^{13}$. The participants reached with one foot in the anterior, posteromedial, and posterolateral directions during standing on the other foot on a central plastic footplate. All testing and practices were performed barefoot with both the left and right limbs to eliminate additional balance and stability from the shoes ${ }^{17}$. Each subject was allowed 6 practice trials in each direction and on each leg prior to formal testing for familiarization, then conducted 3 test trials in each direction and the mean value of the 3 test trials was determined for data analysis. We 
allowed rest on a chair for 3 min between practice and recorded trials, but not between trials. The subject maintained a single-leg stance with hands on the pelvis while pushing a rectangular reach-indicator block with the contralateral leg as far as possible along the 3 directions (Figure 1). The reach distance was recorded to the nearest $0.5 \mathrm{~cm}$ as the point at which the reach-indicator block was pushed closest to the central footplate. The specific testing order was right anterior, left anterior, right posteromedial, left posteromedial, right posterolateral, and left posterolateral (a consistent testing protocol was established to improve the reproducibility of the test).

A trial was classified as invalid if the participant did not return to the starting position, kicked the plate with the reaching foot to gain more distance, failed to maintain a unilateral stance on the platform, stepped on top of the reach indicator for support, or removed her hands from her hips. If an invalid trial occurred, the data were discarded, and the subject repeated the trial.

For normalization, the participants' lower limb length while lying in the supine position (anterosuperior iliac spine to the center of the ipsilateral medial malleolus) was measured in centimeters bilaterally. For data analysis, the reach distance in each direction was normalized to the lower-limb length by calculating the maximized reach distance (\%MAXD) using the formula ( 6 excursion distance/ both lower-limb length $\times 3) \times 100=\%$ MAXD because of leg length differences within individuals ${ }^{18}$. The sum of 6 normalized reach distances (right and left in all 3 directions) was then averaged to generate a composite distance.

\section{Handheld Dynamometer}

A digital handheld dynamometer (HHD; PowerTrack II, JTech Medical, Salt Lake City, UT) was used to measure the maximum voluntary strength in each participant. As in the BBS, the rater was a physical therapist with 5 years of experience. The maximal isometric strength of the bilateral hip extensors, flexors, and abductors, knee extensors and flexors, and ankle dorsiflexors was assessed by physical therapists with 5 years of experience using the PowerTrack II on each limb separately. We did not measure the isometric force of the ankle plantar flexors because handheld dynamometry provides unreliable measures of ankle plantar flexor strength ${ }^{19}$. The testing positions, based on Wang et al. ${ }^{20}$, are described in Table 1. Participants were told to stop contracting when the tester finished counting to 5 seconds because this duration was shown to be adequate for most subjects to reach the maximum force in a previous study ${ }^{21}$. The mean peak value of these 3 measurements was used for the data analysis.

\section{Berg Balance Scale}

To gain an understanding of the participants' static and dynamic balance abilities, assessments were carried out with the BBS, a 14-item summative ordinal scale evaluating postural changes from sitting to standing and vice versa, transfers, sitting balance, and a variety of other standing balance tasks ${ }^{22}$. The rater was a physical therapist with 5 years of experience. Among the 14 items, tandem standing and single-leg standing have been described as the most difficult ${ }^{22}$; in our study, some older females obtained low scores for these items. The BBS has demonstrated excellent
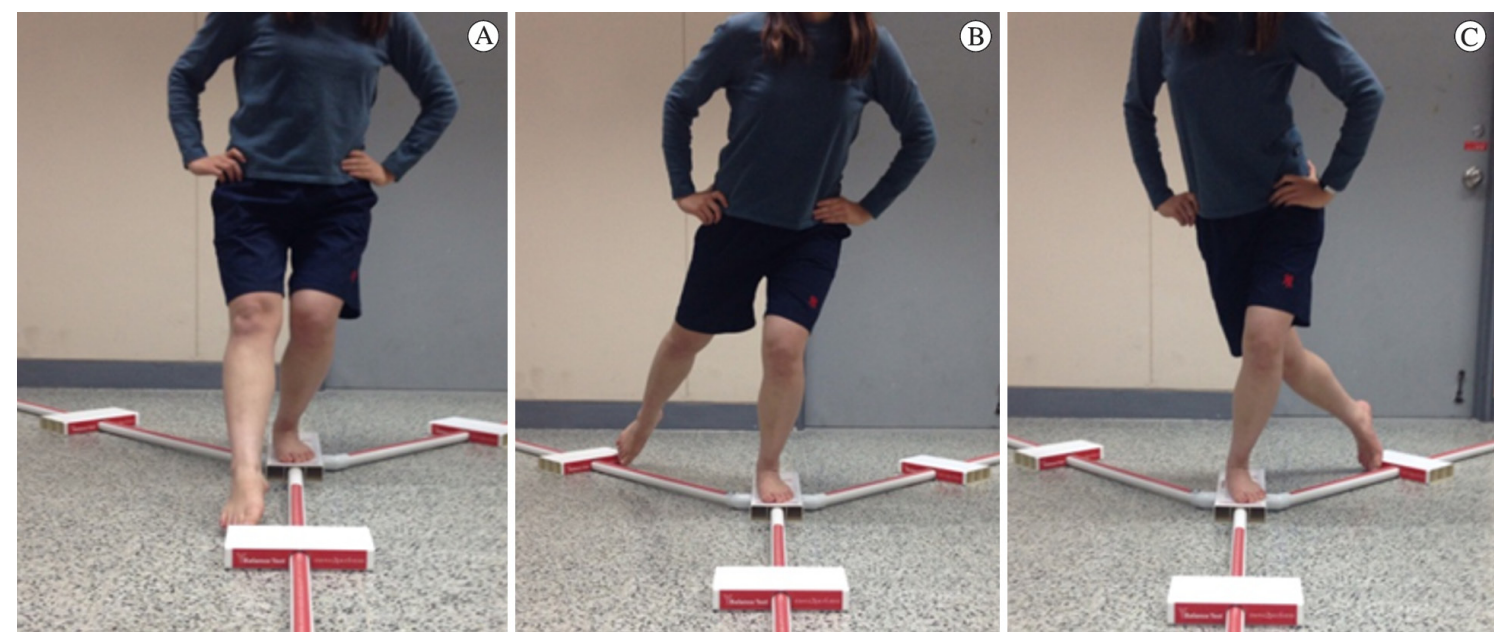

Figure 1. Y Balance Test: (A) anterior, (B) posteriomedial, (C) posteriolateral reach direction. 
Table 1. Muscle-group testing positions.

\begin{tabular}{|c|c|c|c|}
\hline Muscle Group & Starting Position & Testing Position & Dynamometer Placement \\
\hline Hip flexors & Sitting; hips and knees at $90^{\circ}$ & Thigh raised off the seat $10^{\circ}$ & Distal thigh just proximal to knee \\
\hline Knee extensors & flexion; foot not touching floor & $\begin{array}{l}\text { Knee at about } 80^{\circ} \text { flexion while } \\
\text { testing }\end{array}$ & $\begin{array}{l}\text { Front lower leg just proximal to } \\
\text { ankle }\end{array}$ \\
\hline Ankle dorsiflexors & & $\begin{array}{l}\text { Heel on the ground } \\
\text { during dorsiflexion }\end{array}$ & $\begin{array}{l}\text { Distal dorsal medial surface of } \\
\text { the foot }\end{array}$ \\
\hline Knee flexors & $\begin{array}{l}\text { Prone; knees at } 90^{\circ} \text { flexion; } \\
\text { examiner stabilizes the pelvis } \\
\text { with the hand }\end{array}$ & Knee at $90^{\circ}$ flexion while testing & $\begin{array}{l}\text { Posterior aspect of lower leg just } \\
\text { proximal to ankle }\end{array}$ \\
\hline Hip extensors & $\begin{array}{l}\text { Prone; examiner stabilizes the } \\
\text { pelvis with the hand }\end{array}$ & $\begin{array}{l}\text { Hip at } 10^{\circ} \text { extension with knee } \\
\text { straight }\end{array}$ & $\begin{array}{l}\text { Posterior thigh proximal to knee } \\
\text { joint }\end{array}$ \\
\hline Hip abductors & $\begin{array}{l}\text { Side lying; lower knee flexed; } \\
\text { upper knee straight; examiner } \\
\text { stabilizes the pelvis with the hand }\end{array}$ & $\begin{array}{l}\text { Hip at } 30^{\circ} \text { abduction with knee } \\
\text { straight }\end{array}$ & Lateral epicondyle of the femur \\
\hline
\end{tabular}

inter-rater reliability (intraclass correlation coefficient $=0.99$ ) and test-retest reliability (intraclass correlation coefficient $=0.98)^{22}$. However, the BBS may not be the most appropriate test of mobility or balance because of the ceiling effect in active community-living older females.

\section{Statistical analysis}

Data were analyzed using the SPSS software (ver. 18.0; SPSS, Chicago, IL, USA). After testing for a normal distribution using the Kolmogorov-Smirnov test, significant differences between the groups (middle-aged and older females) were identified using the independent ttest for YBT distance and muscle strength. The significance level was set at $p<0.05$ and was adjusted for multiple hypothesis tests $\left(\mathrm{p}_{\text {adj }}<0.008(0.05 / 6)\right.$ and $\left.\mathrm{p}_{\text {adj }}<0.007(0.05 / 7)\right)$. In each group, Pearson's correlation coefficients were used to quantify the linear relationships among YBT composite distance, the BBS score, and muscle strength. The correlation significance level was set at $p<0.01$ for a strong presumption against the null hypothesis. Intraclass correlation coefficients (ICC) were used to quantify test-retest reliability of the YBT. The ICC model $(3,1)$ was used.

\section{Results}

Tables 2 and 3 summarize the mean \pm SD of YBT distance and strength. Same-day intra-rater reliability was also calculated from 3 repeat tests done on day 1 by rater 1 and all measurements were highly reliable ( $\mathrm{ICC}=0.92$ to 0.97 ; Table 2 ). The 3 reach directions for both lower limbs in the YBT and lower limb muscle strength tests were significantly higher and longer in middle-aged females than in older females $\left(\mathrm{p}_{\text {adj }}<0.008\right.$ or $\mathrm{p}_{a d j}<0.007$; Tables 2, 3). The mean BBS score \pm SD of the older females was $55.1 \pm 1.1$ (range: 52-56); the middle-aged females exhibited a perfect BBS score.

In the older group, there was a fair relationship but insignificant correlation was found between the YBT composite distance and the BBS score. Right hip abductor, right knee flexor, and left knee flexor strength were positively correlated with the YBT composite distance.

In the middle-aged group, right hip extensor, left hip extensor, and right knee flexor strength were positively correlated with the YBT composite distance.

\section{Discussion}

Several previous studies reported that older adults have significantly lower limb strength and balance ability than do middle-aged females ${ }^{23}$. The results of the present study indicated that the YBT distance and the lower limb strength in each muscle were significantly lower in older adults than in middle-aged females. However, muscle group strength in the different age groups was inconsistently correlated with the YBT composite distance.

The findings of this study also indicated that the lower limb muscle strength of the older adult group was significantly lower than that of the middle-aged group. Aging causes quantitative and qualitative alterations in the neuromuscular system, especially a generalized loss of skeletal muscle mass and strength. In males, 
Table 2. Y balance test distance (\%MAXD) in both lower limbs between middle-aged and older females.

\begin{tabular}{lcccccc}
\hline \multicolumn{1}{c}{ Direction } & $\begin{array}{c}\text { Middle-aged } \\
\text { Mean(SD) }\end{array}$ & ICC(3,1) & $\mathbf{9 5 \% ~ C I ~}$ & $\begin{array}{c}\text { Older Adult } \\
\text { Mean(SD) }\end{array}$ & ICC(3,1) & 95\% CI \\
Right anterior & $78.2(4.6)^{*}$ & 0.94 & $0.71-0.93$ & $62.4(5.8)$ & 0.95 & $0.76-0.94$ \\
Left anterior & $77.0(4.9)^{*}$ & 0.97 & $0.84-0.96$ & $63.1(5.8)$ & 0.93 & $0.67-0.92$ \\
$\begin{array}{l}\text { Right } \\
\text { posteriomedial }\end{array}$ & $120.9(7.3)^{*}$ & 0.94 & $0.69-0.92$ & $98.2(8.9)$ & 0.96 & $0.78-0.95$ \\
$\begin{array}{l}\text { Left } \\
\text { posteriomedial }\end{array}$ & $119.0(7.3)^{*}$ & 0.92 & $0.65-0.91$ & $97.8(9.5)$ & 0.94 & $0.72-0.93$ \\
$\begin{array}{l}\text { Right } \\
\text { posteriolateral }\end{array}$ & $117.7(8.7)^{*}$ & 0.97 & $0.83-0.96$ & $93.4(10.2)$ & 0.95 & $0.76-0.94$ \\
$\begin{array}{l}\text { Left } \\
\text { posteriolateral }\end{array}$ & $118.6(8.6)^{*}$ & 0.96 & $0.80-0.95$ & $95.0(10.3)$ & 0.94 & $0.72-0.93$ \\
Composite & $105.2(5.5)^{*}$ & & & $85.0(6.9)$ & & \\
\hline
\end{tabular}

$\mathrm{ICC}=$ Intraclass correlation coefficient; $95 \% \mathrm{CI}=95 \%$ confidence interval; Independent t-test is significant at ${ }^{*} \mathrm{p}_{\text {adj }}<0.007(0.05 / 7)$.

Table 3. Strength values (Mean(SD); kg) of muscle groups in middle-aged and older females.

\begin{tabular}{lcccc}
\hline \multicolumn{1}{c}{ Muscle Group } & \multicolumn{2}{c}{ Middle-aged $(n=\mathbf{2 0})$} & \multicolumn{2}{c}{ Older $(n=\mathbf{2 0})$} \\
Right & Left & Right & $56.6(11.3)$ \\
Hip flexor & $74.9(13.6)^{*}$ & $72.8(12.3)^{*}$ & $55.0(12.4)$ & $32.9(8.3)$ \\
Hip extensor & $58.2(16.4)^{*}$ & $54.5(14.0)^{*}$ & $32.5(7.2)$ & $51.9(11.2)$ \\
Hip abductor & $78.2(15.6)^{*}$ & $73.9(13.6)^{*}$ & $53.3(9.8)$ & $36.7(11.2)$ \\
Knee flexor & $57.4(10.5)^{*}$ & $55.8(10.0)^{*}$ & $38.9(11.6)$ & $43.9(9.2)$ \\
Knee extensor & $72.2(17.4)^{*}$ & $67.4(17.0)^{*}$ & $45.5(8.9)$ & $44.2(6.3)$ \\
Ankle dorsiflexor & $62.5(13.1)^{*}$ & $61.1(10.3)^{*}$ & $44.8(7.9)$ & \\
\hline
\end{tabular}

Independent ttest is significant at $* \mathrm{p}_{\text {adj }}<0.008(0.05 / 6)$.

lower limb strength declines gradually ${ }^{24}$, whereas in females it declines sharply after menopause ${ }^{25}$. Many factors associated with inactivity contribute to this decline in lower limb strength, such as a low score on the activities of daily living scale, balance abnormalities $^{26}$, bed rest, or a sedentary lifestyle ${ }^{27}$. A reduction in lower limb strength could have deleterious effects on the performance of basic activities of daily living and contribute to an increased risk of falls $^{28,29}$. Consistent with previous studies, there was a significant difference between the middle-aged and older adult groups. However, Sousa et al ${ }^{30}$ reported that once-weekly sessions of resistance training are sufficient to improve muscle strength. It is important that therapists and other healthcare practitioners recommend appropriate exercises or training programs for the recovery of strength in the elderly.

An exploratory finding was that, across all participants, all directions of the YBT were significantly lower in the older adult group than in the middle-aged group.
Bouillon and Baker ${ }^{10}$ reported that younger females were able to reach approximately $7 \mathrm{~cm}$ farther than middle-aged females during the anterior, anteromedial, and posteromedial directions in the SEBT. Differences between groups may be assumed to be the result of decreased lower extremity strength or range of motion. Thus, we measured lower limb strength and confirmed that the strength of all muscle groups in both lower limbs was less in older than in middle-aged females; this may affect dynamic postural control. Thus, it may be that dynamic postural control can be improved by increasing lower limb strength in older females; however, further study is needed to evaluate targeted strength interventions. Moreover, the decreased distance in older females during YBT performance suggests that older adults have more difficulty than middle-aged adults in maintaining a posture with a single-limb stance on a limited support base (central plastic footplate). The single-limb stance 
is a significant challenge for older adults so caution is needed to prevent falling during YBT performance.

Brauer et al. ${ }^{31}$ assessed the balance of 100 healthy older females with a mean age of $73.0 \pm 5.0$ years and reported that the BBS results indicated a ceiling effect for the groups both with and without a history of falls. In addition, Newton ${ }^{32}$ suggested that modifications should be made to the BBS when it is applied to active older adults. This means that the BBS cannot predict a risk of falling at high levels of balance ability. Participants in this study gained a BBS score close to the maximum ( $>52$ points), and the BBS is not sufficiently sensitive in active older adults. Therefore, the BBS cannot be recommended for this population because of the ceiling effect. The tasks of the BBS in healthy elderly people may not be sufficiently challenging to detect subtle balance deficits, so there is a need for alternative measures, such as the YBT. The BBS is scored on an ordinal scale; however, the YBT distance is measured on a ratio scale. In addition, an advantage of the YBT is its ability to simultaneously perform both functional performance testing and training.

In our study, a significantly strong relationship was noted between the YBT composite distance and the knee flexor strength in both the older and middle-aged groups. The SEBT showed that the greatest amount of knee flexion ROM occurred during performance of the anteromedial reach ${ }^{33}$. To perform the YBT, subjects lean forward and backward to maintain their balance, and gravity acting on the upper body creates a large knee-flexion moment. Consequently, the knee flexor may contribute to a greater YBT distance when the body sway is converted from forward to backward. This finding is supported by previous research that indicated increased hamstring activity when a leg is extended backwards; the trunk flexes to maintain balance ${ }^{32}$. The YBT reaching included 2 of the 3 directions (i.e. posteromedial and posterolateral) when the leg is extended backwards. Hubbard et al. ${ }^{34}$ reported that posteriomedial and posteriolateral excursion during the SEBT are correlated with hip abduction and extension strength. However, we found a correlation between the YBT composite distance and the lower limb strength. The findings of this study showed that the hip abductor was positively correlated with the YBT composite distance in the older adult group, but that the hip extensor was correlated with the YBT composite distance in the middle-aged group. An increased hip flexion range of motion is required for a greater reaching distance in SEBT, which may have led to an increased demand on hip extensor strength to maintain postural control ${ }^{35}$. Based on our results, it may be inferred that low hip extensor strength $(32.7 \mathrm{~kg}$ ) could be substituted by strong hip abductor strength $(53.6 \mathrm{~kg})$, as the hip abductor can contribute to the YBT distance in the older group. These findings suggest that differences between groups may play a role separate from balance strategy according to the changes in muscle strength with aging. Therefore, clinicians should consider different treatments according to age by assessing performance in the YBT. There were significant correlations between the YBT test and strength measures for both age groups but, in fact, the relationships were only significant in $25 \%$ of the muscle groups tested in the older group (3/12) and younger groups (3/12). A post hoc power analysis determined that at least 19 subjects were necessary to establish statistical significance at a power of .90 , which supports the significance of our findings.

Our study had some limitations. When interpreting the results, the constraints of our cross-sectional research design must be considered. We recruited a group of females with no history of falls. The BBS as a comparison measure of balance was inappropriate because of a ceiling effect. However, we used BBS as a dynamic balance measurement to assess the test in active older females. We did not measure the range of motion in the lower extremities because the available lower extremity range of motion for ankle dorsiflexion and the hip internal and external range of motion that participants exhibited did not influence the reaching distance $^{36}$. We did not consider a small potential effect of fatigue during the YBT. We supervised the movements of body sway for fear of falling by visual judgment during YBT performance. Although visual judgment is used widely in the clinical setting, further study would be useful to provide objective validity using a motion analysis system. Additionally, future studies should assess relationships between each direction distance in YBT and lower limb strength. Although the YBT is not available for balance assessment in all clinical facilities, the present findings provide a fundamental framework from which to expand and develop the YBT.

\section{Conclusions}

The present findings provide clinicians with useful information regarding the relative contribution of muscle strength to YBT performance when evaluating dynamic balance, but differences were observed between the 
middle-aged and older adult groups. In older females, the decreased ability for dynamic balance by YBT distance could be associated with declined muscle strength. We recommend that therapists and other healthcare practitioners use YBT performance in the development of rehabilitation and training programs in older people; however, further studies are needed to determine the clinical utility of this test.

\section{References}

1. Kallman DA, Plato CC, Tobin JD. The role of muscle loss in the age-related decline of grip strength: cross-sectional and longitudinal perspectives. J Gerontol. 1990;45(3):M82-8. http://dx.doi.org/10.1093/geronj/45.3.M82. PMid:2335723

2. Cabell L, Pienkowski D, Shapiro R, Janura M. Effect of age and activity level on lower extremity gait dynamics: an introductory study. J Strength Cond Res. 2013;27(6):150310. http://dx.doi.org/10.1519/JSC.0b013e318269f83d. PMid:22964857

3. Sattin RW, Lambert Huber DA, DeVito CA, Rodriguez JG, Ros A, Bacchelli S, et al. The incidence of fall injury events among the elderly in a defined population. Am J Epidemiol. 1990;131(6):1028-37. PMid:2343855.

4. Bergeron E, Clement J, Lavoie A, Ratte S, Bamvita JM, Aumont F, et al. A simple fall in the elderly: not so simple. J Trauma. 2006;60(2):268-73. http://dx.doi.org/10.1097/01. ta.0000197651.00482.c5. PMid:16508481

5. Thelen DG, Schultz AB, Alexander NB, Ashton-Miller JA. Effects of age on rapid ankle torque development. J Gerontol A Biol Sci Med Sci. 1996;51(5):M226-32. http:// dx.doi.org/10.1093/gerona/51A.5.M226. PMid:8808994

6. Woodhull-McNeal AP. Changes in posture and balance with age. Aging (Milano). 1992;4(3):219-25. PMid:1420405.

7. Lord SR, Ward JA. Age-associated differences in sensorimotor function and balance in community dwelling women. Age Ageing. 1994;23(6):452-60. http://dx.doi.org/10.1093/ ageing/23.6.452. PMid:9231937

8. Mälklä E, Impivaara O, Heliövaara J, Maatela, J. The physical activity of healthy and chronically ill adults in Finland at work, at leisure and during commuting. Scand J Med Sci Sports. 1994;4(1):82-7. http://dx.doi.org/10.1111/j.1600-0838.1994. tb00409.x.

9. Bouillon LE, Sklenka DK, Driver AC. Comparison of training between 2 cycle ergometers on dynamic balance for middle-aged women. J Sport Rehabil. 2009;18(2):31626. PMid: 19561372.

10. Bouillon LE, Baker JL. Dynamic balance differences as measured by the Star Excursion Balance Test between adult-aged and middle-aged women. Sports Health. 2011;3(5):466-9. http://dx.doi.org/10.1177/1941738111414127. PMid:23016044

11. Steffen TM, Hacker TA, Mollinger L. Age- and genderrelated test performance in community-dwelling elderly people: six-minute walk test, berg balance scale, timed up \& go test, and gait speeds. Phys Ther. 2002;82(2):128-37. PMid:11856064.
12. Bogle Thorbahn LD, Newton RA. Use of the Berg Balance Test to predict falls in elderly persons. Phys Ther. 1996;76(6):576-83. PMid:8650273.

13. Shumway-Cook A, Baldwin M, Polissar NL, Gruber W. Predicting the probability for falls in community-dwelling older adults. Phys Ther. 1997;77(8):812-9. PMid:9256869.

14. Muir SW, Berg K, Chesworth B, Speechley M. Use of the Berg Balance Scale for predicting multiple falls in community-dwelling elderly people: a prospective study. Phys Ther. 2008;88(4):449-59. http://dx.doi.org/10.2522/ ptj.20070251. PMid: 18218822

15. Plisky PJ, Gorman PP, Butler RJ, Kiesel KB, Underwood FB, Elkins B. The reliability of an instrumented device for measuring components of the star excursion balance test. N Am J Sports Phys Ther. 2009;4(2):92-9. PMid:21509114.

16. Butler RJ, Southers C, Gorman PP, Kiesel KB, Plisky PJ. Differences in soccer players' dynamic balance across levels of competition. J Athl Train. 2012;47(6):616-20. http:// dx.doi.org/10.4085/1062-6050-47.5.14. PMid:23182008

17. Gribble PA, Hertel J. Effect of lower-extremity muscle fatigue on postural control. Arch Phys Med Rehabil. 2004;85(4):589-92. http://dx.doi.org/10.1016/j.apmr.2003.06.031. PMid:15083434

18. Robinson RH, Gribble PA. Support for a reduction in the number of trials needed for the star excursion balance test. Arch Phys Med Rehabil. 2008;89(2):364-70. http://dx.doi. org/10.1016/j.apmr.2007.08.139. PMid:18226664

19. Arnold CM, Warkentin KD, Chilibeck PD, Magnus CR. The reliability and validity of handheld dynamometry for the measurement of lower-extremity muscle strength in older adults. J Strength Cond Res. 2010;24(3):815-24. http://dx.doi. org/10.1519/JSC.0b013e3181aa36b8. PMid:19661831

20. Wang CY, Olson SL, Protas EJ. Test-retest strength reliability: hand-held dynamometry in community-dwelling elderly fallers. Arch Phys Med Rehabil. 2002;83(6):811-5. http:// dx.doi.org/10.1053/apmr.2002.32743. PMid:12048660

21. Bohannon RW. Testing isometric limb muscle strength with dynamometers. Crit Rev Phys Med Rehabil. 1990;2:75-86.

22. Berg KO, Wood-Dauphinee SL, Williams JI, Maki B. Measuring balance in the elderly: validation of an instrument. Can J Public Health. 1992;83(Suppl 2):S7-11. PMid:1468055.

23. Weirich G, Bemben DA, Bemben MG. Predictors of balance in young, middle-aged, and late middle-aged women. J Geriatr Phys Ther. 2010;33(3):110-7. PMid:21155505.

24. Doherty TJ. Invited review: Aging and sarcopenia. J Appl Physiol (1985). 2003;95(4):1717-27. http://dx.doi.org/10.1152/ japplphysiol.00347.2003. PMid:12970377

25. Hughes VA, Frontera WR, Roubenoff R, Evans WJ, Singh MA. Longitudinal changes in body composition in older men and women: role of body weight change and physical activity. Am J Clin Nutr. 2002;76(2):473-81. PMid:12145025.

26. Baumgartner RN, Koehler KM, Gallagher D, Romero L, Heymsfield SB, Ross RR, et al. Epidemiology of sarcopenia among the elderly in New Mexico. Am J Epidemiol. 1998;147(8):755-63. http://dx.doi.org/10.1093/oxfordjournals. aje.a009520. PMid:9554417

27. Cruz-Jentoft AJ, Baeyens JP, Bauer JM, Boirie Y, Cederholm T, Landi F, et al. Sarcopenia: European consensus on definition and diagnosis: Report of the European Working Group on 
Sarcopenia in Older People. Age Ageing. 2010;39(4):412-23. http://dx.doi.org/10.1093/ageing/afq034. PMid:20392703

28. Lawrence RH, Jette AM. Disentangling the disablement process. J Gerontol B Psychol Sci Soc Sci. 1996;51(4):S173-82. http://dx.doi.org/10.1093/geronb/51B.4.S173. PMid:8673646

29. Barry BK, Carson RG. The consequences of resistance training for movement control in older adults. J Gerontol A Biol Sci Med Sci. 2004;59(7):730-54. http://dx.doi. org/10.1093/gerona/59.7.M730. PMid:15304540

30. Sousa N, Mendes R, Abrantes C, Sampaio J, Oliveira J. Is once-weekly resistance training enough to prevent sarcopenia? J Am Geriatr Soc. 2013;61(8):1423-4. http:// dx.doi.org/10.1111/jgs.12387. PMid:23937497

31. Brauer SG, Burns YR, Galley P. A prospective study of laboratory and clinical measures of postural stability to predict community-dwelling fallers. J Gerontol A Biol Sci Med Sci. 2000;55(8):M469-76. http://dx.doi.org/10.1093/ gerona/55.8.M469. PMid:10952371

32. Newton RA. Balance screening of an inner city older adult population. Arch Phys Med Rehabil. 1997;78(6):587-91. http:// dx.doi.org/10.1016/S0003-9993(97)90423-8. PMid:9196465
33. Earl JE, Hertel J. Lower-extremity muscle activation during the Star Excursion Balance Tests. J Sport Rehabil. 2001;10:93-104.

34. Hubbard TJ, Kramer LC, Denegar CR, Hertel J. Correlations among multiple measures of functional and mechanical instability in subjects with chronic ankle instability. J Athl Train. 2007;42(3):361-6. PMid:18059991.

35. Robinson R, Gribble P. Kinematic predictors of performance on the Star Excursion Balance Test. J Sport Rehabil. 2008;17(4):347-57. PMid:19160909.

36. Nakagawa L, Hoffman M. Performance in static, dynamic, and clinical tests of postural-control in individuals with recurrent ankle sprains. J Sport Rehabil. 2004;13:255-68.

\author{
Correspondence \\ Jae-Seop Oh \\ INJE University College of Biomedical Science and \\ Engineering Department of Physical Therapy \\ 607 Obang-Dong, Gimhae, Gyeongsangnam-Do, \\ 621-740, South Korea \\ E-mail: ysrehab@inje.ac.kr
}

